\title{
Enhancing the Public Health Role of Community Pharmacists - A Qualitative Research Utilising the Theoretical Domains Framework
}

\author{
Chijioke O. Agomo, BPharm, MSc, MRes, DProf, FHEA ${ }^{1}$; James Ogunleye, PhD ${ }^{1}$; Jane Portlock, PhD, FRPharmS, FHEA ${ }^{2}$
}

${ }^{1}$ The Institute for Work Based Learning, Middlesex University; ${ }^{2}$ University of Sussex

\begin{abstract}
Introduction: The current global coronavirus (Covid-19) pandemic has once again highlighted the need to enhance the role of community pharmacists in public health. In 2012, the World Health Organisation (WHO) estimated that global deaths due to noncommunicable diseases (NCDs) as about 38 million (68\%). Most of these conditions are preventable through public health initiatives involving community pharmacists. This study aims to explore strategies enhancing the public health role of community pharmacists.

Methods: Data was collected through telephone interviews, supported by Skype (audio), and recorded using the 'HD Call Recorder for Skype'. The qualitative data software package NVivo (version 10) was used for the storage, retrieval and analysis of data. The constant comparative method of data analysis was used. In addition, the Theoretical Domains Framework (TDF) was used to underpin the research throughout. Results: This study identified a number of strategies that could enhance the public health role of community pharmacists, some of which include: integrating undergraduate healthcare programmes; broadening the public health knowledge of students and pharmacists; pharmacists working alongside other healthcare professionals; teaching communication methods to students and pharmacists; teaching the use of new technologies and social media; etc. In addition, most of the 14 domains of TDF and several of their constructs were captured in the interview. Conclusions: To enhance the public health role of community pharmacists, it is necessary to develop pharmacists' capacity in several areas, particularly as it relates to, the use new technologies and social media in public health; enhancing training of pharmacists/students in public health; empowering pharmacists in public health; as well as teaching communication methods to students and pharmacists. Part of the strategy will also be, to integrate healthcare programmes through interdisciplinary initiatives, and changing the undergraduate pharmacy curriculum to increase its public health content.
\end{abstract}

Keywords: public health policy, pharmacy, qualitative research, theoretical domains framework, TDF

\section{Introduction}

The current global coronavirus (COVID-19) pandemic has once again highlighted the need to enhance the role of community pharmacists in public health. ${ }^{1}$ As of $14^{\text {th }}$ July 2020 , the global situation in numbers of coronavirus was put at 12, 768, 307 cases (566 654 deaths), with the rate of infection increasing daily at an alarming rate in many parts of the world. ${ }^{2}$ With regards to non-communicable diseases, in 2012, the World Health Organisation (WHO) estimated that global deaths due to non-communicable diseases (NCDs) was about 38 million $(68 \%) .^{3}$ However, most of these conditions are preventable through public health initiatives involving community pharmacists.

In terms of contemporary policy context in the world of pharmacy it has been argued that pharmacy education and practice have changed from their initial narrow product-centred focus to the present patient-centred focus in many countries globally, although to different degrees. ${ }^{4}$ According to the Royal College of Nursing, patient-centred (or person-centred) care is about focusing care on the needs of the person rather than the needs of the service. ${ }^{5}$ In other words, the person or patient is seen an equal partner in the planning of care, and his or her opinions are important and are respected. ${ }^{5}$

Corresponding author: Chijioke O. Agomo, BPharm, MSc, MRes, DProf, FHEA; The Institute for Work Based Learning, Middlesex University, The Burroughs, London NW4 4BT United Kingdom. Email: cagomo@hotmail.com
However, there is now a demand from healthcare professions and various governments for a public health-oriented healthcare education and practice that prepares the present healthcare practitioner (including pharmacists) to see beyond the individual patient to his community and society. ${ }^{4}$ This is important as this can help enhance the quality of patient care (including patient safety), improve the patient experience, as well as reduce costs of health care. ${ }^{6}$

A similar change in pharmacy education and practice have also been made, ${ }^{7}$ such that, will necessitate pharmacy education to comprise the right public health orientation to prepare and empower pharmacists with the necessary knowledge, skills, attitudes, and values crucial for contributing to public health, both at the micro and macro levels, regardless of their practice setting. ${ }^{4}$ Micro-level public health functions have been defined to include those activities provided by pharmacists such as, disease management, health and wellness screening, immunisations, medication therapy management etc., while macro-level public health functions include examples such as, assessment, policy development, and assurance at the population-based level. ${ }^{8}$ Added to the increasing expectation for pharmacists to be knowledgeable in both pharmacy and population-based healthcare, is also the need for future pharmacists to understand the wider concept of public health, with the objective of improving health at a population level. ${ }^{9,10}$

Still, in a UK service-focused study, ${ }^{11}$ it was identified that community pharmacists around the globe were providing a wide range of roles in public health. They included: smoking 
cessation services; infection control and prevention; promoting cardiovascular health and blood pressure control; provision of emergency hormonal contraception (EHC); prevention and management of drug abuse, misuse and addiction; and healthy eating and lifestyle advice. This study contributed to the decisions of an important UK public health paper, ${ }^{12}$ with its findings further confirmed in a later study. ${ }^{13}$ More so, it has been recognised that community pharmacists are in a prime position to help combat health issues, many of which are identified risk factors for chronic diseases. ${ }^{14}$ This is important, as community pharmacies are easily accessible and provide a convenient and less formal environment for those who cannot or do not wish to visit other kinds of health services. ${ }^{14,15}$

Still, in a study conducted in the UK, it was identified that despite the sharp increase in the number of pharmacy schools, this has not had much impact on the teaching of public health to students, particularly as public health remains an optional module in many UK schools of pharmacy. ${ }^{16}$. In some schools, public health was integrated into other modules; in general, the curricula of most pharmacy schools were often dominated by traditional modules designed to enhance students' knowledge and skills in the sciences, dispensing, production, research, law and ethics, and clinical pharmacy. ${ }^{16}$ This however contrasted with the evidence from many developed nations, that indicated that many pharmacy schools have incorporated public health as one of the core subjects taught in their undergraduate curriculum. ${ }^{17,18}$

Nevertheless, pharmacists will be expected by healthcare providers and funders to evaluate public health policies for costs and effectiveness as well as collaborate with government agencies in formulating public health policies. ${ }^{19}$ On the effectiveness of community pharmacists in public health, the literature suggests that the essential public health service where pharmacy presence is most felt is in evaluating the effectiveness, accessibility, and the quality of personal and population-based health services. ${ }^{20}$ Next is to link people to needed personal health services and assure the provision of health care when otherwise unavailable. ${ }^{20}$

Aim: To explore strategies enhancing the public health (including the medication management, surveillance, referral, and follow-up) role of community pharmacists.

\section{Method}

Design

This is a qualitative study involving the use of in-depth semistructured telephone interviews with community pharmacists and other healthcare professionals. The sample size for the study was determined during the process; hence, the interviews were continued until no new information was yielded or data became saturated. ${ }^{21,22}$ A convenient sample of participants were selected, based on their availability and willingness to participate in the study. Informed consent was obtained from participants prior to inclusion in the study. Data was collected through telephone interviews, supported by Skype (audio); using an interview guide that incorporated open-ended questions. ${ }^{23}$ Interviews were recorded with HD Call Recorder for Skype, and lasted approximately 20-30 minutes. These interviews were facilitated by the three members of the research team (CA, JO, and JP). CA conducted the in-depth semistructured interviews, consistent with the method suggested for such interviews. ${ }^{24}$ Researchers JO and JP reviewed the potential topics to determine their suitability. ${ }^{25}$ Participants were assured that confidentiality was guaranteed. ${ }^{26}$ This meant explaining to the participants exactly what was meant by anonymity and confidentiality, ${ }^{26,27}$ and ensuring that informants were not identified by quotes from the data, hence, the use of initials to identify participants in the results. ${ }^{28}$

\section{Analysis}

The qualitative data software package NVivo (version 10) was used for the storage, retrieval and analysis of data. CA transcribed the interviews verbatim. Experienced researchers (JO \& JP) independently verified the coding procedure, as part of the validity check on the interpretative process. In the analysis, thematic analysis was used. ${ }^{29,30}$ Essentially, the phases include familiarising yourself with your data; generating initial codes; searching for themes; reviewing themes; defining and naming themes and producing the reports. ${ }^{29}$

For this analysis, sentences were used as the units of analysis. Initial codes were assigned to data that was of interest to the analytical framework through process of repeated reading, the emphasis being on including all relevant data. In some cases, multiple codes were assigned to each unit of analysis. As the analysis progressed, the number of new codes created diminished, indicating the point of saturation - which is the point of when no new information is yielded. ${ }^{21}$ The next step was a process of code refinement where codes were considered together to identify patterns and connections to form what became subcategories, which were then connected across higher order categories. ${ }^{31}$ Emerging themes were reviewed for counterthemes (themes that oppose another themes). ${ }^{32}$ In addition, some numerical data were presented in the analysis. ${ }^{33}$

The Theoretical Domains Framework (TDF) was used to underpin the research throughout (see Table 1). The TDF is an integrative framework, which is as a vehicle to help apply theoretical approaches to interventions aimed at behavioural change. ${ }^{34,35}$ This is particularly important as enhancing the role of community pharmacists in public health can help pharmacists use behavioural change tools to improve healthcare and health outcomes. ${ }^{34}$ Such behaviours may be those of healthcare workers, for example, implementation of evidence-based practice of patients, medication adherence of the general population, or even smoking cessation and increasing physical activity. ${ }^{34}$ Moreover, as some of the anticipated strategies might also involve changing pharmacists' attitudes and behaviours towards the public health role, one would therefore anticipate that a greater appreciation and application of these behavioural change models by pharmacists, their trainers and possibly employers, will lead to better outcomes in public health 
practice. To enable implementation of health care interventions, the TDF can be used prospectively ${ }^{36}$ as well as retrospectively in theory-based process evaluation. ${ }^{34}$ Hence, the TDF brings together the models and theories of behavioural change. ${ }^{37}$ According to Jones, et al., the TDF was originally comprised of 12 domains, however, this was later increased to 14 domains - each domain obtained from the constructs of many behavioural change theories. ${ }^{37}$ A domain is defined as comprising, a set of similar theoretical constructs (see Table 1). ${ }^{38}$

Table 1: The Refined Theoretical Domains Framework

Reproduced from Cane, O'Connor \& Michie, Implementation Science, $2012 .^{34}$

\begin{tabular}{|c|c|}
\hline Domain/Definition* & Constructs \\
\hline $\begin{array}{l}\text { Knowledge } \\
\text { An awareness of the existence of something }\end{array}$ & $\begin{array}{ll}\text { - } & \text { Knowledge (including knowledge of } \\
\text { condition/scientific rationale) } \\
\text { - } \quad \text { Procedural knowledge } \\
\text { - } \quad \text { Knowledge of task environment }\end{array}$ \\
\hline $\begin{array}{l}\text { Skills } \\
\text { An ability or proficiency acquired through practice }\end{array}$ & $\begin{array}{ll}- & \text { Skills } \\
- & \text { Skills development } \\
- & \text { Competence } \\
- & \text { Ability } \\
- & \text { Interpersonal skills } \\
- & \text { Practice } \\
- & \text { Skill assessment }\end{array}$ \\
\hline $\begin{array}{l}\text { Social/Professional Role and Identity } \\
\text { A coherent set of behaviours and displayed personal qualities of an individual } \\
\text { in a social or work setting }\end{array}$ & $\begin{array}{ll}\text { - } & \text { Professional identity } \\
\text { - } & \text { Professional role } \\
\text { - } & \text { Social identity } \\
\text { - } & \text { Identity } \\
\text { - } & \text { Professional boundaries } \\
\text { - } & \text { Professional confidence } \\
\text { - } & \text { Group identity } \\
\text { - } & \text { Leadership } \\
\text { - } & \text { Organisational commitment }\end{array}$ \\
\hline $\begin{array}{l}\text { Beliefs about capabilities } \\
\text { Acceptance of the truth, reality, or validity about an ability, talent, or facility } \\
\text { that a person can put to constructive use }\end{array}$ & $\begin{array}{ll}- & \text { Self-confidence } \\
- & \text { Perceived competence } \\
\text { - } & \text { Self-efficacy } \\
\text { - } & \text { Perceived behavioural control } \\
- & \text { Beliefs } \\
- & \text { Self-esteem } \\
- & \text { Empowerment } \\
- & \text { Professional confidence }\end{array}$ \\
\hline $\begin{array}{l}\text { Optimism } \\
\text { The confidence that things will happen for the best or that desired goals will be } \\
\text { attained }\end{array}$ & $\begin{array}{ll}- & \text { Optimism } \\
\text { - } & \text { Pessimism } \\
\text { - } & \text { Unrealistic optimism } \\
\text { - } & \text { Identity }\end{array}$ \\
\hline $\begin{array}{l}\text { Beliefs about Consequences } \\
\text { Acceptance of the truth, reality, or validity about outcomes of a behaviour in a } \\
\text { given situation }\end{array}$ & $\begin{array}{ll}- & \text { Beliefs } \\
\text { - } & \text { Outcome expectancies } \\
\text { - } & \text { Characteristic of outcome expectancies } \\
\text { - } & \text { Anticipated regret } \\
\text { - } & \text { Consequents }\end{array}$ \\
\hline $\begin{array}{l}\text { Reinforcement } \\
\text { Increasing the probability of a response by arranging a dependent relationship, } \\
\text { or contingency, between the response and a given stimulus }\end{array}$ & $\begin{array}{ll}- & \text { Rewards (proximal/distal. valued/not valued. } \\
\text { probably/improbable) } \\
\text { - } \quad \text { Incentives }\end{array}$ \\
\hline
\end{tabular}




\begin{tabular}{|c|c|}
\hline $\begin{array}{l}\text { Reinforcement (continued) } \\
\text { Increasing the probability of a response by arranging a dependent relationship, } \\
\text { or contingency, between the response and a given stimulus }\end{array}$ & $\begin{array}{ll}- & \text { Punishment } \\
\text { - } & \text { Consequents } \\
\text { - } & \text { Reinforcement } \\
\text { - } & \text { Contingencies } \\
\text { - } & \text { Sanctions }\end{array}$ \\
\hline $\begin{array}{l}\text { Intentions } \\
\text { A conscious decision to perform a behaviour or a resolve to act in a certain way }\end{array}$ & $\begin{array}{ll}- & \text { Stability of intentions } \\
\text { - } & \text { Stages of change model } \\
\text { - } & \text { Transtheoretical model and stages of change }\end{array}$ \\
\hline $\begin{array}{l}\text { Goals } \\
\text { Mental representations of outcomes or end states that an individual wants to } \\
\text { achieve }\end{array}$ & $\begin{array}{ll}- & \text { Goals (distal/proximal) } \\
- & \text { Goal priority } \\
- & \text { Goal/target setting } \\
- & \text { Goals (autonomous/controlled) } \\
- & \text { Action planning } \\
- & \text { Implementation intention }\end{array}$ \\
\hline $\begin{array}{l}\text { Memory, Attention and Decision Processes } \\
\text { The ability to retain information, focus selectively on aspects of the } \\
\text { environment and choose between two or more alternatives }\end{array}$ & $\begin{array}{ll}\text { - } & \text { Memory } \\
\text { - } & \text { Attention } \\
\text { - } & \text { Attention control } \\
\text { - } & \text { Decision making } \\
\text { - } & \text { Cognitive overload/tiredness }\end{array}$ \\
\hline $\begin{array}{l}\text { Environmental Context and Resources } \\
\text { Any circumstance of a persons' situation or environment that discourages or } \\
\text { encourages the development of skills and abilities, independence, social } \\
\text { competence, and adaptive behaviour }\end{array}$ & $\begin{array}{ll}- & \text { Environmental stressors } \\
- & \text { Resources/material resources } \\
\text { - } & \text { Organisational culture/climate } \\
\text { - } & \text { Salient events/critical incidents } \\
\text { - } & \text { Person x environment interaction } \\
- & \text { Barriers and facilitators }\end{array}$ \\
\hline $\begin{array}{l}\text { Social Influences } \\
\text { Those interpersonal processes that can cause individuals to change their } \\
\text { thoughts, feelings, or behaviours }\end{array}$ & $\begin{array}{ll}- & \text { Social pressure } \\
\text { - } & \text { Social norms } \\
\text { - } & \text { Group conformity } \\
\text { - } & \text { Social comparisons } \\
\text { - } & \text { Group norms } \\
\text { - } & \text { Social support } \\
\text { - } & \text { Power } \\
\text { - } & \text { Intergroup conflict } \\
\text { - } & \text { Alienation } \\
\text { - } & \text { Group identity } \\
- & \text { Modelling }\end{array}$ \\
\hline $\begin{array}{l}\text { Emotion } \\
\text { A complex reaction pattern, involving experiential, behavioural, and } \\
\text { physiological elements, by which the individual attempts to deal with a } \\
\text { personally significant matter or event }\end{array}$ & $\begin{array}{ll}- & \text { Fear } \\
- & \text { Anxiety } \\
- & \text { Affect } \\
- & \text { Stress } \\
- & \text { Depression } \\
- & \text { Positive/negative affect } \\
- & \text { Burn-out }\end{array}$ \\
\hline $\begin{array}{l}\text { Behavioural Regulation } \\
\text { Anything aimed at managing or changing objectively observed or measured } \\
\text { actions }\end{array}$ & $\begin{array}{ll}- & \text { Self-monitoring } \\
\text { - } & \text { Breaking habit } \\
\text { - } & \text { Action planning }\end{array}$ \\
\hline
\end{tabular}




\section{Results}

Characteristics of healthcare professionals interviewed

In terms of characteristics, fifteen healthcare professionals (including ten pharmacists, one pre-registration pharmacist, three general practitioners and a nurse) were included in the interviews. Nine (60\%) of the healthcare professionals interviewed were female, while majority of participants (seven) [46.7\%] aged 50 to 59 years. Following the interview with the healthcare professionals, a number of themes emerged from the data analysis.

\section{Enhancing the public health role of community pharmacists} According to the WHO, activities that enhance public health capacities and services provide conditions that enable individuals to continue to be healthy, improve their wellbeing, or prevent the worsening of their health. ${ }^{39}$ Participants suggested a number of strategies needed to enhance the public health role of community pharmacists.

\section{Creating awareness and enhancing training}

Two participants highlighted the need to create more awareness [knowledge], as well as enhancing the public health training of pharmacists [knowledge and skills]. While a GP partner would like pharmacists to be more accessible to the public [environmental context and resources], a GP locum reinforced the need for public awareness, in addition, suggesting for a referral system to be used [social influences team working], to help minimise the current wastage in the National Health Service (NHS) [environmental context and resources].

"...we see a lot of patients with minor illnesses that come to the GP and I think this is a waste of time...You see them, especially in the winter months... patients can be educated more...like give them a list of conditions that, 'these things, you don't really need to see your GP...crowding the A\&E, go to your pharmacist'. Your pharmacist obviously is the one that will say, that thing is beyond me, and you go and see your GP. But, I think also, maybe providing...triage services" [GP-CHY]

\section{Empowering pharmacists in public health activities}

Still, the wider issue of empowerment by the public, the commissioning and regulatory bodies [beliefs about capabilities] was also highlighted by two pharmacists who felt that not much can be achieved without the support of these very important groups.

"So, whoever is acting in the capacity of the function for today, is taking responsibility for every aspect of public health,....and they should be remunerated accordingly and not the business...So, there are many, many roles pharmacists can do, if value is place on them to do it, if they're remunerated accordingly..." [P-OL]
The use of Independent Pharmacist Practitioners in public health

According to a UK pharmacists' organisation, enabling the development of Independent Pharmacist Practitioners (IPPs) who are not attached to any employers ${ }^{40}$ could help change the status quo, and motivate pharmacists to enhance their role in public health. ${ }^{41}$ On the role of the IPPs in public health, that is, pharmacists who are independently employed, e.g. locums, pharmacist-visitors, etc. a mixture of comments were received. While of one of the pharmacist participants would like to have locum pharmacists working in GP surgeries [skills practice/skills development; social influences - team working]; a GP participant argued that the use of independent practitioners is a common feature in general practice.

"...It's just like for us as doctors, it is not everybody that is affiliated to a practice... but, when they need us, because they know where we are, we go and help them out. So, in the same way, if there is a list of IPPs..." [GP-CHY]

\section{Asserting ownership of qualifications}

One participant (a US based pharmacist, and formerly a UK preregistration pharmacist) raised the issue of ownership of public health qualifications [knowledge and skills], which he reckoned often belonged to the practitioner rather than the practice. Using the past Ebola outbreak in West Africa as an example, one of the participants described IPPs as 'stakeholders in public health', particularly as in this case, IPPs (not pharmacies) had to work collaboratively with other practitioners to contain the situation. He cited another example with the global Vitamin D deficiency, (which may be relevant in the current fight against COVID-19), ${ }^{42}$ and which he argued could also be tackled by IPPs, hence, the need for pharmacists and IPPs to take up leadership positions in public health.

"Every pharmacist, by virtue of their training, has a role to play in public health...if a pharmacist is trained on how to immunise, it is the individual pharmacist that immunises, [and] it is he that has the qualification to immunise." [USPCHD]

For another participant, the advantage with this model lies in the fact that practitioners will be working for the benefit of patients, rather than being constrained by some of the limitations associated with commercially orientated pharmacy establishments [social influences - alienation/organisational commitment].

"...I think that could intentionally be a good thing, because hopefully, they are actually working for the benefit of the patient, as opposed to maybe some sort of business." [HP/TP-NKT].

There were however some concerns over how IPPs would be practising, with one pharmacist participant raising some questions regarding the quality of their training [knowledge and skills] as well as the kind of support they will be receiving [environmental context and resources; reinforcement], 
describing IPPs as 'silo-practitioners'. In the case of the nurse participant, the role of IPPs in public health will only develop if the NHS is privatised [environmental context and resources].

Teaching communication methods to students and pharmacists Yet, a number of studies have identified the need for healthcare practitioners to improve their communication techniques [skills]. ${ }^{43,44}$ In terms of benefits, some of the responses indicated that this would help develop the professional skills of pharmacists [skills], particularly with regard to teaching students and pharmacists how to communicate with people from different ethnic groups and health conditions.

"Communication method is very important, just like saying bedside manner. Isn't it, of a doctor? ...They talked to us about communication skills as doctors that we need to be empathetic...a need for confidentiality, you know...because you're looking at people from all kinds of life, religion, beliefs." [GP-CHY]

\section{Integrating healthcare programmes}

On the integration of healthcare programmes, there is now an emphasis on interdisciplinary initiatives in the management of many causes of ill health. ${ }^{45}$ In terms of inter-professional education, it is driven mainly by health professional education associations. ${ }^{46}$ Based on the responses most participants would like interdisciplinary initiatives between health professions to be a way forward.

\section{Benefits associated with integrated learning and practice}

When it comes to the benefits of integrated learning, some of the suggestions included, it can help break down barriers, and facilitate communication between healthcare practitioners [social influences - team working]. Moreover, it can foster better understanding of roles and skill-sets, can facilitate trust between practitioners, can widen the professional field and the knowledge base of pharmacists, as well as strengthen practitioners' ability to pass on information easily [knowledge, skills and team working].

"It would actually boost their field...makes it much easier to pass information around..." (P-VIV).

According to a GP participant, allowing undergraduate healthcare students to study together [social influences team working] can also enable graduates to appreciate some of the roles, responsibilities and boundaries of other health professionals [professional identity/boundaries/role], particularly as it relates to long-term management of chronic conditions:

“...A lot of times when we go to college or university...we just learn about ourselves, our roles...We are not intertwined with other...health professionals, who play an important part...when you get to working with them, you have no clue how to handle them so, taking certain courses together will help." [GP-CHY]
This line of thought was also supported by another GP participant [GP-NN] and a pharmacist [P-JO], both with previous experience in integrated teaching overseas. Other than managing health outcomes, some of the responses indicated that integrated work patterns can also help pharmacists get better career progression and fulfilment in practice [beliefs about capabilities - empowerment, optimism; and social influences - leadership]. Yet, some of the benefits associated with integrated practice, particularly as it relates to financial rewards to GP practices, could also be affected depending on where they are located - rural or urban [environmental context and resources - constraints]. This point is in line with the opinion of a legal expert in pharmacy, particularly as it relates to the challenges associated with establishing community pharmacies in GP practices. ${ }^{47}$

"They should be anyway...Rural GPs have pharmacists working within the same building, and the GPs are responsible for the financial aspects and they make a lot of money out of it. But GPs in urban areas, they are not allowed to. They will stop it." [GPP-SIM]

Still, another pharmacist participant [P-SOL) argued that GP practices that employ pharmacists seemed to make less prescribing errors [behavioural regulation - self-monitoring]. As this might be linked with enhanced communication and transfer of information between healthcare providers and healthcare settings; ${ }^{43}$ being in-house meant that pharmacists were able to correct any errors on prescriptions before they left GP practices. In addition, these GP practices were also more likely to follow the National Institute for Clinical Excellence (NICE) guidance [behavioural regulation: moderators of intention - behaviour gap] in their prescribing patterns, hence, helping to minimise harm to patients.

Furthermore, prescribers were also more likely to consider the price of medicines and other items in their prescribing habits [environmental context and resources], which can then translate to large savings to GP practices and the wider NHS. In addition, pharmacists employed in GP practices, particularly those with sound clinical knowledge and skills [knowledge and skills], we learnt, were often in a better position to advise doctors regarding the best therapeutic choices in complex clinical issues than GP practices without an in-house pharmacist [beliefs about capabilities - perceived competence]. Nevertheless, not all practices are able to employ in-house pharmacists, due mainly to financial constraints [environmental context and resources].

\section{Concerns regarding integrated learning}

Although, one of the pharmacist participants was aware of some of the advantages associated with integrated learning, for example, the ability to develop collaborative practices with other health professionals, however, she was also concerned about the logistics associated with this arrangement [material resources (availability and management), and social influences - crew resource management]. Her main concern being that often these other schools (e.g. medicine and nursing) tended to 
have large classes, which could then be difficult to manage across schools. There is also the issue of breaks and calendars, which she argued, were not always aligned between schools and faculties.

Another concern from another pharmacist [P-NKT] was that integrated learning could also lead to the dominance and the prioritisation of other healthcare students during lectures [professional role and identity], which could then put pharmacy students in a difficult situation [emotion - anticipated regret, fear and threat]. Although, another participant recognised the need for integration, he was however concerned that unlike in the hospital were such interactions seemed natural, particularly during ward rounds; in the community setup this type of integration might be difficult with GPs [social influences: conflict - competing demands, conflicting roles].

Changing the curriculum to increase its public health content On changing the curriculum, some earlier studies have identified the need to enhance the public health content of pharmacy curriculum. ${ }^{11,48}$

\section{Enhancing public health knowledge and skills}

According to the pre-registration pharmacist participant, as many of the common chronic conditions are linked with lifestyles [memory, attention and decision processes - decision making], it was important to enhance both the public health knowledge and the collaborative skills of healthcare professionals [knowledge and skills]. This will therefore mean spending money [environmental context and resources] on the public health education of health professionals, as a preventative measure, rather than on certain therapeutic medicines.

"...every healthcare professional want to do public health...but, these ailments are linked together. We're looking at diet and we're looking at smoking, smoking is linked to COPD or emphysema, as we used to know it in the day and chronic bronchitis and things like that. If we look at the lifestyle, exercise and the food we eat, that goes on into diabetes...And how many people are overweight? And that's leading into those with heart conditions...I will rather, instead of asking the money on simvastatin and things like that, can we not just train our healthcare professionals... from Day 1...No 1, we don't give drugs, No 2, we teach them how to live a healthy lifestyle. I know drug companies will not be happy with this [laughs], but if at the end of the day that will help the patient, it is a preventative measure." [PRFLY]

Even though, one of the GP participants was not too sure about the nature of the undergraduate pharmacy curriculum [knowledge], other than that it was about medicines, she however envisaged some of the advantages that could emanate with the enhanced public health knowledge of pharmacists [knowledge], particularly as it relates to preventative care, and managing health demands and financial pressures. This becomes relevant when you also consider the fact that in some instances, community pharmacists are even nearer to patients than the GPs, ${ }^{49}$ a point raised also by the GP participant.

Nonetheless, this lack of awareness of the nature of pharmacists' undergraduate training by other health professionals was also evident from the responses of another GP participant, who argued that pharmacists of the 21st century would need to be independent practitioners [skills competence], if they were to be taken seriously as public health practitioners. Mentioning also that there is a lot of stress on healthcare professionals [emotion - stress], particularly, the GPs; she however reckoned that this can create an opportunity for pharmacists' enhanced role in public health.

"...there is a lot of pressure on the other community health professionals, mainly the GPs. If the pharmacists are able to help and take the pressure off and have more education and training to be more relevant in health protection and health provision, that's all good..." [GP-NN]

\section{Enhancing public health through the use of new technologies and social media}

A UK paper has described how the public health role of community pharmacists could be enhanced through the use of new technologies. ${ }^{50}$ Regarding the use of new technologies in public health, the views were also varied, with some of the participants identifying beneficial impacts on the wider public health activities provided by pharmacists [skills], and a few participants highlighting concerns about confidentiality and safety [emotion - fear and threat].

\section{Benefits associated with the use of new technologies and social media}

As it relates to benefits, one participant spoke about the use of popular software such as Twitter, Instant Messaging and Facebook in public health activities; citing an example where Instant Messaging is used in non-pharmacy organisations such as Currys ${ }^{\circledR}$. On the other hand, the nurse practitioner saw the use of new technologies as an avenue which community pharmacists could use to attract the younger population, who are often hard to reach to the pharmacy [memory, attention and decision processes - attention]. Yet, another participant saw the use of new technologies in public health as innovative, and likely to bring benefits to community pharmacy public health campaigns [behavioural regulation - facilitator].

“...We are living in such a technologically advanced world, everything is online, and everything is on Twitter or Facebook or whatever...but, in terms of public health, I don't know, maybe, if there was a number you could call that [had] more pharmacists at the other end...You could ask for help." [P-NKT]

According to the US based participant, the use of new technologies could help enhance the public health role of community pharmacists, for example, to record public health activities from community pharmacies [memory, attention and decision processes], as well as using visual technologies to help 
patients learn how to use medical devices [beliefs about capabilities: self-efficacy], even from a distance.

While one of the GP participants had argued that not making use of new technologies could amount to waste of time and resources [environmental context and resources]; a pharmacist participant reasoned that the use of new technologies could be extended to other pharmacy services, such as, the Medicines Use Reviews (MURs) in patients' homes [knowledge, and beliefs about capabilities: self-efficacy], which could then be linked to GP practice, pharmacy and hospital computers [social influences - team working]. According to one of the participants, it seems logical that UK pharmacy schools should include the use of new technologies in the undergraduate curriculum, bearing in mind that the pharmacists of today will have no choice, but to face the challenges of the computer age [skills - competence / ability /skill assessment, practice / skills development].

"People need to know, because when they qualify they can't escape new technologies" (P-SOL).

This need to embrace the use of new technologies was also supported by many other participants, who argued that there was no way the pharmacy profession could move forward [intentions], without pharmacists embracing modern technologies:

"Obviously, as we advance it seems like the computer is here to stay and the robot is here to stay. So, definitely, it needs to be on the curriculum." [GP-NA]

Suggestions on the use of new technologies and social media in public health

In terms of specifics, some of the new technologies recommended included, the "development of diagnostic tools" (P-PO), the use of the "EPS 2 system" (P-VIV), "telephone systems", social media tools such as the "Smart Messaging Service (SMS)", "Twitter" and "Facebook" (P-JO), with one participant suggesting the use of "robots" (N-ART). Strangely, there was nothing to suggest from the interviews that participants themselves were making use of these tools in their practices.

"...Technology in diagnosis is important, because if you look at the minor ailment scheme, which we do, it is more or less guesswork. So, a technology...that tells you that look, this is a bacterial sore throat and so should be referred to the doctor, or that is this cough, is reflective of cancer that should be referred or that...the cough is probably due to dust inhalation or something like that. Yes." [P-PO]

As well as these, pharmacists involvement in public health was also linked to increasing prescription only medicines (POM) to pharmacy medicines (P) switches. However, for one of the participants, this was not just about treatment, it was also about preventing long-term diseases, which could then save lives through lifestyle changes, etc. [beliefs about capabilities]. Again, this benefit was not for doctors alone, but also for other healthcare professionals and the entire health system [social influences - team working and organisational development]. Nonetheless, to enable community pharmacists achieve these public health aims, one pharmacist participant argued also that it was imperative to enhance the undergraduate pharmacy curriculum, so as to enable pharmacists to identify disease patterns easily, even at a global level [skills]. "...You could be part of the global team necessary to enhance global health." (P-JO).

\section{Discussion}

Through this project, it has been possible to explore some of the strategies needed to enhance the public health role of community pharmacists (incorporating TDF as a framework for analysis). Regarding the adoption of new technologies and social media in practice, it has been argued that social networks can be great tools to obtain professional knowledge, as well as disseminate information globally. ${ }^{51}$ Moreover, platforms such as Twitter can offer real-time access to news while allowing people to leave their opinions. ${ }^{51}$ On the other hand, Linkedln could be used to build a professional profile and get in contact with other professionals. ${ }^{51}$ Despite these benefits, it has also been argued that the number of pharmacists using social media in practice is minimal, raising the possibility that pharmacy practice in general is not taking up the opportunity offered by social media. ${ }^{51}$

With the increasing popularity of apps, with estimates in 2014 put at 138 billion downloads worldwide, there are signs that UK pharmacists are slowly catching up with these new technologies in practice. ${ }^{52}$ In community pharmacy, a number of pharmacists are now using apps designed to calculate an individual's chance of developing cardiovascular (CV) disease in the next ten years by recording information on height, weight, smoking history and family heart history; a Diabetes UK risk score app for calculating an individual's risk of developing type 2 diabetes; a Diabetes UK app for type 1 or type 2 diabetes daily blood glucose monitoring; an app for electrocardiograph (ECG) reading within 30 seconds; an app designed as a game to test a person's memory function, and another app which reminds patients when to take their medicine and prompts them if they forget. In addition, there is now a wellbeing app for psychological support for all NHS staff, including those working in primary care, during the COVID-19 outbreak. ${ }^{53}$

Nonetheless, it appears sound to also put into consideration the emotional impact [fear as well as threat] which the use of new technologies and social media could have on pharmacists, particularly with regards to their job security (P-PO). Having said that, it seems also reasonable to argue that UK pharmacy schools should likewise reflect the teaching of these new ways of delivering public health services strongly in their curricula. This need becomes even more important during this current coronavirus pandemic. While most of the interview participants were in support of the use of new technologies and social media in practice, a few of them, particularly the older ones, were less 
supportive of their use in practice. Some of their concerns centred around privacy, which is also an environmental constraint, and confidentiality - possibly due to lack of beliefs about capabilities of pharmacists and their staff.

Still, it has been noted that in practice, that little attempt is made by healthcare professionals to assess patients' understanding of any health advice given. ${ }^{54}$ This could be due to lack of skills, beliefs about capabilities or environmental context and resources, particularly as it relates to competing tasks and time constraints. The nurse participant [N-CHM] highlighted the same concern with community pharmacists, 'At the moment...most pharmacists...they just give you your usual supply of prescription. They don't advise any more'. However, pharmacists signposting patients to manufacturers' YouTube videos on good device techniques, which empower patients through knowledge or even using online tools such as Skype, Zoom, etc., to teach patients [beliefs about capabilities], could further demonstrate pharmacists' ability to employ readily available new technologies and social media to enhance their role in public health.

Nevertheless, within the UK's NHS, there has been a steady transfer of care from specialist hospital doctors to primary care doctors, especially the GPs, ${ }^{55}$ mainly to take healthcare delivery nearer to patients as well as to contain and reduce the cost of treatment. There is no doubt that this has further increased the workload of GPs [time constraints], with some of this work within the public health domain (e.g. health education, immunisation, medicines use/clinical reviews, etc.). The review of knowledge and information ${ }^{56,57}$ revealed that enhancing the public health role of community pharmacists can significantly reduce the cost of treatment as well as the workload of other healthcare professionals, by reducing GP and A\&E appointments for minor conditions that can easily be managed by pharmacists.

A UK pharmacy association supports this initiative, which they believe will help enhance both the clinical and the public health roles of community pharmacists. ${ }^{58}$ While it might appear realistic that GPs should transfer some of their minor clinical and public health roles to pharmacists, so as to enable them to focus on more complicated clinical and public health cases, this is not always an easy transition. The reason is that while it is a lot easier for GPs to take on some of the specialist doctors' roles due to the uniformity of undergraduate training, this is not the case with pharmacists, whose undergraduate training has been developed traditionally as a science rather than a clinical/public health programme. In many UK pharmacy schools, it has been noted that public health is often taught to students as an optional module or integrated with other topics. ${ }^{16}$ There is now a need for public health to be presented as a core module in the curricula of UK Schools of Pharmacy, so as to broaden and advance the knowledge base and skill set of pharmacists in public health. There is also a need for Schools of Pharmacy to further develop their curricula, particularly as it relates to the use of motivational tools, for example, the Transtheoretical
Model of Change (TTM), ${ }^{59,60}$ in lifestyle and addictive behaviours [motivation; intentions and goals].

On the other hand, the need to broaden and enhance the public health (including clinical pharmacy) training of undergraduate students and then pharmacists ${ }^{61}$ supports the recent move in the UK to employ pharmacists in GP practices. ${ }^{62}$ Hopefully, pharmacists working in GP practices will help enhance the professional image of pharmacists, particularly as pharmacists' link with the 'shop environment' seems not to have helped their public health role agenda. Still, it seems sensible that community pharmacists might have to transfer some aspects of their dispensing roles to well-trained and competent dispensers and technicians or even robotic dispensers [environmental context and resources], a point previously argued for elsewhere. ${ }^{63,49}$

At the University of Manchester, UK, health students have now developed an initiative to promote inter-professional education [social influences (norms) - team working], by arranging numerous events each year, ranging from lectures to healthcare-based quizzes that focus on a variety of issues. ${ }^{64}$ Most of the interview participants were in support of promoting interdisciplinary initiatives in pharmacy education and later in practice [social influences - team working]. In terms of benefits, they included its ability to encourage inter-professional learning and practice, easy transfer of knowledge between practitioners [knowledge and skills enhancement], minimising wastage of resources and duplication of efforts in some institutions [reducing environmental constraints through efficient resource management], facilitating patients' care services [beliefs about capabilities and empowerment], as well as its ability to enhance the profile of pharmacists [social/professional role and identity].

One of the concerns raised by one of the participants [P-ART] was the problem of logistics when it comes to integrating undergraduate pharmacy education with other healthcare professions [environmental context and resources]. While integrated learning might be a challenge for stand-alone Schools of Pharmacy without a nearby medical, dental or nursing school; yet, it is possible for these schools to liaise with nearby health facilities, for example GP practices, local health centres and hospitals, as a way forward. Again, exchange training programmes and internships with other schools and health institutions could also be helpful, as well as the use of online technologies, for example Skype, Zoom or other conferencing software, to enhance communication skills, manage logistics, build rapport and understanding among professions, as well as facilitate integrated learning and exchange of ideas.

Nevertheless, remunerating pharmacists directly for providing public health services can help enhance their role in public health, ${ }^{65}$ as against the present system, where only pharmacists' employers are remunerated for public health services provided by pharmacists. Supporting this initiative, one of the interview participants [P-OL] had argued that, 'they (pharmacists) should be remunerated accordingly and not the business'. One benefit 
of this model is that it limits some of the constraints often associated with employer-led public health services, such as the use of targets and financial considerations. ${ }^{66}$

To address some of these challenges, the profession might also need to consider promoting the establishment of Healthy Living Pharmacies [skills]. ${ }^{67}$ In order to support this role, community pharmacists might need to reach out to the community, and running public health programmes in libraries or other community meeting places, at the same time, developing their own expertise in public health. A good example of this reach out could be, pharmacists/pharmacy engaging in employee health fairs - defined as, services provided to employees at local businesses, including cholesterol screenings, blood pressure screenings, [coronavirus screening], and height, weight, and body mass index measurement; (with) written results given to patients. ${ }^{68}$

Regarding recommendation for further studies, these findings could be made more illuminating by exploring the perspectives of healthcare users. Further researcher on the need for a dual pharmacy degrees and the use of new technologies and social media might be needed to explore how these could help enhance the public health role of community pharmacists.

The TDF and several of its constructs ${ }^{38}$ were very useful in analysing this data. However, some of the limitations of the study included, difficulty associated with analysing interviews, which is very time-consuming. Moreover, the pre-knowledge of some of the respondents may also have affected both the issues raised $^{69}$ and the respondents' willingness to share certain views. ${ }^{70}$ The study findings could have been enhanced by including a wider range of healthcare practitioners, for example, hospital consultants, specialist public health practitioners/consultants, dieticians, even the public, etc.

\section{Conclusions}

This study identified a range of strategies that could potentially enhance the public health role of community pharmacists in the UK, particularly as it relates to the use new technologies and social media in public health; enhancing training of pharmacists/students in public health; creating awareness about public health activities; empowering pharmacists; developing independent pharmacist practitioners; as well as teaching communication methods to students and pharmacists. Part of the strategy will also be, to integrate healthcare programmes through interdisciplinary initiatives, and changing the undergraduate pharmacy curriculum to increase its public health content. Interestingly, most of the 14 domains of the TDF and several of their constructs ${ }^{38}$ were captured in the interviews. Applying these constructs to the identified strategies, it seems necessary to develop pharmacists' capacity in several areas, particularly as it relates to: knowledge, skills, social/professional role and identity of pharmacists; enhancing optimism, beliefs about capabilities and beliefs about consequences, as well as streamlining intentions and goals within the profession. Yet, it might also be necessary to manage social influences (norms) and the emotion of pharmacists, enhancing reinforcement (particularly as it relates to rewards and incentives), as well as the environmental context and resources available to community pharmacists.

Acknowledgements: None.

Funding/support: None.

Conflict of interest: None.

\section{References}

1. Zhang G, Hu C, Luo L, et al. Clinical features and short-term outcomes of 221 patients with COVID-19 in Wuhan, China. J Clin Virol. 2020;127:104364. doi: 10.1016/j.jcv.2020.104364.

2. World Health Organization. Coronavirus disease (COVID-19) - Situation Report - 175. [Internet]. Geneva: World Health Organization; 2020. Available from: https://www.who.int/docs/defaultsource/coronaviruse/situation-reports/20200713-covid-19sitrep-175.pdf?sfvrsn=d6acef25_2 (Accessed July 27, 2020)

3. World Health Organization. NCD Mortality and Morbidity. [Internet]. Geneva: World Health Organization; 2015. Available from:

http://www.who.int/gho/ncd/mortality_morbidity/en/ (Accessed July 27, 2020).

4. Addo-Atuah J. Making a case for a public health orientation in global pharmacy education and practice in the context of the Millennium Development Goals (MDGs). Curr Pharm Teach \& Learn. 2014;6(5):723-729.

5. Royal College of Nursing. What person-centered care means. 2020. Available from: https://rcni.com/hostedcontent/rcn/first-steps/what-person-centred-care-means (Accessed August 13, 2020).

6. Berwick DM, Nolan TW, and Whittington J. The triple aim: care, health, and cost. Health Aff. 2008;27(3):759-769.

7. Bush PJ, Johnson KW. Where is the public health pharmacists? Am J Pharm Ed. 1979;43:249-253.

8. Truong $\mathrm{H}$, Patterson BY. Professional and educational initiatives, supports, and opportunities for advanced training in public health. Am J Pharm Ed. 2010;74(7):Article 122.

9. Rijk AD, Raak AV, and Made JVD. A new theoretical model for cooperation in public health settings: the RDIC model. Quality Health Res. 2007;17(8):1103-16.

10. Jackson JK, Sweidan M, Spinks JM, et al. Public health Recognising the role of Australian pharmacists. J Pharm Pract Res. 2004;34(4):290-2.

11. Agomo $\mathrm{C}$. The role of community pharmacists in public health: a scoping review of the literature. J Pharm Health Serv Res. 2012;3:25-33.

12. Public Health England. Consolidating and developing the evidence base and research for community pharmacy's contribution to public health: A progress report from Task Group 3 of the pharmacy and public health forum. London: Public Health England, 2014.

13. Agomo C, Udoh A, Kpokiri E, et al. Community pharmacists' contribution to public health: assessing the global evidence base. Clinical Pharmacist. 2018;10(4), online. DOI: 10.1211/CP.2018.20204556 
14. Department of Health. Pharmacy in England: Building on strengths - delivering the future. London: Stationery Office, 2008.

15. McGuire TR, Leypoldt M, Narducci WA, et al. Accessing rural populations: Role of the community pharmacist in a breast and cervical cancer screening programme'. J Eval Clin Pract. 2007;13(1):146-149.

16. Agomo C, Portlock J, and Ogunleye J. Inclusion of Public Health in the Pharm Curriculum in the United Kingdom: Content Analysis. Preprints. 2018; 2018110050. doi: 10.20944/preprints201811.0050.v1.

17. Crawford SY. Pharmacists' roles in health promotion and disease prevention. Am J Pharm Educ. 2005;69(4):69. Article 73.

18. Fincham JE. Public health, pharmacy, and the Prevention Education Resource Center (PERC) Am J Pharm Educ. 2007;71(5) Article 104.

19. Dolinsky D, Crawford S, and Ried D, et al. Social and Administrative Sciences Supplemental Educational Outcomes Based on CAPE 2004'. 2007. Available from: http://www.aacp.org/resources/education/documents/soci alandadmindec06.pdf (Accessed July 20, 2020).

20. Strand MA, Tellers J, Patterson A, et al. The achievement of public health services in pharmacy practice: A literature review. Res Soc Admin Pharm. 2016;12:247-256.

21. Morse JM. Determining sample size. Qual Health Res. 2000;10:3-5.

22. Cline RR. Data collection methods. In: RR. Aparasu (ed.) Research methods for pharmaceutical practice and policy. London: Pharmaceutical Press; 2011. p. 143-157.

23. Miles MB, Huberman AM. Qualitative data analysis: An expanded sourcebook. London: Sage, 1994.

24. McCracken G. The long interview. Thousand Oaks: Sage, 1988.

25. Burton D. Design issues in survey research. In: D. Burton (ed.) Research training for social scientists. London: Sage Publications; 2000. p. 292-306.

26. Fox M, Martin P, Green G. Doing practitioner research. London: Sage, 2007.

27. Costley C, Elliott G, Gibbs P. Doing Work Based Research. London: Sage, 2010.

28. Ford S. and Reutter L. Ethical dilemmas associated with small samples. J Adv Nurs. 1990; 15(2):187-191.

29. Braun V, Clarke V. Using thematic analysis in psychology. Qual Res Psychol. 2006;3(2):77-101.

30. Caulfield L, Hill J. Analysing the Data: Qualitative Analysis. In L. Caulfield and J. Hill (eds.) Criminological Research for Beginners: A Student's Guide. Abingdon: Routledge, 2014.

31. Burnard P. A method of analysing interview transcripts in qualitative research. Nurse Educ Today. 1991;11:461-466.

32. Abu-Omar SM, Weiss MC, Hassell K. Pharmacists and their customers: A personal or anonymous service? Int J Pharm Pract. 2000;8:135-43.

33. Seale C, Silverman D. Ensuring rigour in qualitative research. Eur J Publ Health. 1997;7:379-84.

34. Cane J, O'Connor D, Michie S. Validation of the theoretical domains framework for use in behaviour change and implementation research. Implement Sci. 2012;7:37.
35. Duncan EM, Francis JJ, Johnston $M$, et al. Learning curves, taking instructions, and patient safety: Using a theoretical domains framework in an interview study to investigate prescribing errors among trainee doctors. Implement Sci. 2012;7:86.

36. Dyson J, Lawton R, Jackson C, et al. Development of a theory-based instrument to identify barriers and levers to best hand hygiene practice among healthcare practitioners. Implement Sci. 2013;8:111.

37. Michie S. Development and Validation of the Theoretical Domains Framework. (n.d.) Available from: https://ktcanada.ohri.ca/workshop_tdf/TDF_Michie.pdf (Accessed July 27, 2020).

38. Michie S, Johnston M, Abraham C, et al. Making psychological theory useful for implementing evidence based practice: A consensus approach. Qual Saf Health Care. 2005;14:26-33.

39. World Health Organization Regional Office of Europe. Public Health Services. [Internet] Denmark: World Health Organization; 2015. Available from:

http://www.euro.who.int/en/health-topics/Healthsystems/public-health-services/public-health-services (Accessed August 19, 2020)

40. Pharmacists' Defence Association. The PDA Road Map. 2013. Available from: http://www.thepda.org/pdf/consultation/english-road-map.pdf (Accessed August 24, 2020).

41. American Pharmacists Association. Independent MTM Pharmacist. 2008. Available from:

http://www.pharmacist.com/sites/default/files/files/mtm_ developing_a_indie_practice.pdf (Accessed August 24, 2020).

42. National Institute for Health and Care Excellence. COVID-19 rapid evidence summary: Vitamin D for COVID-19. 2020. Available from:

https://www.nice.org.uk/advice/es28/resources/covid19rapid-evidence-summary-vitamin-d-for-covid19-pdf1158182526661 (Accessed August 19, 2020)

43. Roughead EE, Kalisch LM, Ramsay E, et al. Continuity of care: When do patients visit community healthcare providers after leaving hospital? Int Med J. 2011;41(9):662667.

44. Rowlands G. Health literacy and public health: A framework for developing skills and empowering citizens. Perspect Public Health. 2012;132(1):23-24.

45. News Team. Interprofessional working must be a priority, say MPs. Pharm J. 2012;289:619.

46. World Health Organization. Framework for Action on Interprofessional Education \& Collaborative Practice. [Internet]. Geneva: World Health Organization; 2010. Available from: https://apps.who.int/iris/bitstream/handle/10665/70185/ WHO_HRH_HPN_10.3_eng.pdf;jsessionid=3B96087EEE2128 3B15765A98FF7963A3?sequence=1 (Accessed August 25, 2020).

47. Reissner D. Setting Up a Pharmacy on GP Premises: The Law. 2015. Available from: http://www.pharmaceuticaljournal.com/career/career-qa/setting-up-a-pharmacy-ongp-premises-the-law/20068279.article (Accessed August 25, 2020). 
48. Eades CE, Ferguson JS, O'Carroll RE. Public health in community pharmacy: A systematic review of pharmacist and consumer views. BMC Public Health. 2011;11:Article 582.

49. Torjesen I. How Do We Ensure Pharmacists Have the Skills They Need for Their Expanding Role?' 2015. Available from: http://www.pharmaceutical-journal.com/news-andanalysis/news/how-do-we-ensure-pharmacists-have-theskills-they-need-for-their-expanding-role/20069084.article (Accessed July 27, 2020).

50. Agomo C. Telemedicine: Improving health services through technology. Pharm J. 2008;281:103-105.

51. Safdar A. Don't be scared to use social media. Clinical Pharmacist. 2015;7(2):26.

52. Andalo D. Using apps in community pharmacy. Pharm J. 2015;295:152-153.

53. Pharmaceutical Services Negotiating Committee. COVID-19 support: Free access to wellbeing apps. 2020. Available from: https://psnc.org.uk/our-news/covid-19-support-freeaccess-to-wellbeing-apps/ (Accessed August 19, 2020)

54. Schwartzberg JG, Cowett A, VanGeest J, et al. Communication techniques for patients with low health literacy: A survey of physicians, nurses, and pharmacists. Am J Health Behav. 2007;31(Suppl 1):S96-S104.

55. Martin S, Smith PC, Gravelle H, et al. Evidence: Do quality improvements in primary care reduce secondary Care Costs? 2011. Available from: http://www.health.org.uk/sites/health/files/DoQualitylmpr ovementsInPrimaryCareReduceSecondaryCareCosts_summ ary.pdf (Accessed July 27, 2020).

56. Baqir W, Learoyd T, Sim A, et al. Cost analysis of a community pharmacy 'minor ailment scheme' across three primary care trusts in the North East of England. J Public Health (Oxf). 2011;33(4):551-555.

57. Pharmacy Research UK. Community Pharmacy Management of Minor Illness. 2014. Available from: https://pharmacyresearchuk.org/wpcontent/uploads/2014/01/MINA-Study-Final-Report.pdf (Accessed July 27, 2020).

58. Pharmacists' Defence Association. Two Heads Are Better than One - PDA Seeks to Secure a Second Pharmacist in every Pharmacy. 2015. Available from: http://www.thepda.org/pdf/insight/2015-spring-insightcommunity.pdf?PHPSESSID=1e7efbc04360791c727c90765a 29d793 (Accessed July 27, 2020).

59. Prochaska JO, DiClemente CC. 'Towards a Comprehensive Model of Change' in W.R. Miller and N. Heather (eds.) Treating Addictive Disorders: Processes of Change. New York: Plenum Press, 1986.
60. Prochaska JO. Strong and weak principles for progressing from pre-contemplation to action on the basis of twelve problem behaviours. Health Psychol. 1994;13(1):47-51.

61. Agomo C. Pharmacy Students must be better Prepared for their Future Careers. 2015. Available from: http://www.pharmaceuticaljournal.com/opinion/correspondence/pharmacy-studentsmust-be-better-prepared-for-their-futurecareers/20068915.article (Accessed July 27, 2020).

62. Robinson S. Employ thousands of pharmacists in GP surgeries, urge professions' leaders. 2015. Available from: http://www.pharmaceutical-journal.com/your-rps/employthousands-of-pharmacists-in-gp-surgeries-urge-professionsleaders/20068134.article (Accessed July 27, 2020).

63. Bradley F, Schafheutle EI, Willis SC, et al. Changes to supervision in community pharmacy: Pharmacist and pharmacy support staff views. Health Soc Care Community. 2013;21(6):644-654

64. Owens LE. How Students at the University of Manchester are Promoting Inter-Professional Education. 2016. Available from: http://www.pharmaceutical-

journal.com/opinion/blogs/how-students-at-the-universityof-manchester-are-promoting-inter-professionaleducation/20201389.blog (Accessed August 25, 2020).

65. Scottish Government. Prescription for excellence: A vision and action plan for the right pharmaceutical care through integrated partnerships and innovation 2013. 2013. Available from:

http://www.scotland.gov.uk/Resource/0043/00434053.pdf (Accessed July 27, 2020).

66. Bush J, Langley CA, Wilson KA. The corporatization of community pharmacy: Implications for service provision, the public health function, and pharmacy's claims to professional status in the United Kingdom. Res Soc Admin Pharm. 2009;5(4):305-318.

67. Kennedy B. PHE commits to doubling HLPs in five years. 2015. Available from:

http://www.chemistanddruggist.co.uk/news/phe-renewscommitment-pharmacy (Accessed July 27, 2020).

68. Doucette WR, McDonough RP, Mormann MM, et al. Threeyear financial analysis of pharmacy services at an independent community pharmacy. J Am Pharm Assoc. 2012;52(2):181-187.

69. Anderson $\mathrm{C}$. Health promotion by community pharmacists: Perceptions, realities and constraints. J Soc Admin Pharm. 1998;15:10-22.

70. De Young M. An inquiry into community pharmacists' views of patient communication. J Soc Admin Pharm. 1996;13:121-30. 